\title{
Urokinase-Type Plasminogen Activator Receptor as a Potential PET Biomarker in Glioblastoma
}

\author{
Morten Persson $^{1}$, Mette K. Nedergaard ${ }^{1,2}$, Malene Brandt-Larsen ${ }^{1}$, Dorthe Skovgaard ${ }^{1}$, Jesper T. Jørgensen ${ }^{1}$, \\ Signe R. Michaelsen ${ }^{2}$, Jacob Madsen ${ }^{1}$, Ulrik Lassen ${ }^{3}$, Hans S. Poulsen ${ }^{2}$, and Andreas Kjaer ${ }^{1}$ \\ ${ }^{I}$ Department of Clinical Physiology, Nuclear Medicine, and PET and Cluster for Molecular Imaging, Rigshospitalet and University of \\ Copenhagen, Copenhagen, Denmark; ${ }^{2}$ Department of Radiation Biology, Finsen Center, Rigshospitalet, Copenhagen, Denmark; and \\ ${ }^{3}$ Department of Oncology, Finsen Center, Rigshospitalet, Copenhagen, Denmark
}

\begin{abstract}
Glioblastoma is one of the most malignant types of human cancer, and the prognosis is poor. The development and validation of novel molecular imaging biomarkers has the potential to improve tumor detection, grading, risk stratification, and treatment monitoring of gliomas. The aim of this study was to explore the potential of PET imaging of the urokinase-type plasminogen activator receptor (UPAR) in glioblastoma. Methods: The uPAR messenger RNA expression of tumors from 19 glioblastoma patients was analyzed, and a cell culture derived from one of these patients was used to establish an orthotopic xenograft model of glioblastoma. Tumor growth was monitored using bioluminescence imaging. Five to six weeks after inoculation, all mice were scanned with small-animal PET/CT using two new UPAR PET ligands ( ${ }^{64} \mathrm{Cu}-\mathrm{NOTA}-\mathrm{AE} 105$ and $\left.{ }^{68} \mathrm{Ga}-\mathrm{NOTA}-\mathrm{AE} 105\right)$ and, for comparison, O-(2-18 F-fluoroethyl)-L-tyrosine ( $\left.{ }^{18} \mathrm{~F}-\mathrm{FET}\right)$. One MRI scan was obtained for each mouse to confirm tumor location. The UPAR specificity of ${ }^{64} \mathrm{Cu}-\mathrm{NOTA}-\mathrm{AE} 105$ was confirmed by alignment of hematoxylin- and eosin-stained and UPAR immunohistochemistrystained slides of the brain with the activity distribution as determined using autoradiography. Results: uPAR expression was found in all 19 glioblastoma patient tumors, and high expression of UPAR correlated with decreased overall survival $(P=0.04)$. Radiolabeling of NOTA-AE105 with ${ }^{64} \mathrm{Cu}$ and ${ }^{68} \mathrm{Ga}$ was straightforward, resulting in a specific activity of approximately $20 \mathrm{GBq} / \mu \mathrm{mol}$ and a radiochemical purity of more than $98 \%$ for ${ }^{64} \mathrm{Cu}-\mathrm{NOTA}-\mathrm{AE} 105$ and more than $97 \%$ for ${ }^{68}$ Ga-NOTA-AE105. High image contrast resulting in clear tumor delineation was found for both ${ }^{68} \mathrm{Ga}-\mathrm{NOTA}-\mathrm{AE} 105$ and ${ }^{64} \mathrm{Cu}-\mathrm{NOTA}-\mathrm{AE} 105$. Absolute uptake in tumor was higher for ${ }^{18}$ F-FET $(3.5 \pm 0.8$ percentage injected dose $[\% \mathrm{ID}] / \mathrm{g})$ than for ${ }^{64} \mathrm{Cu}-\mathrm{NOTA}-A E 105(1.2 \pm 0.4 \% \mathrm{\%} / \mathrm{g})$ or ${ }^{68 \mathrm{Ga}-N O T A-A E 105}$ $(0.4 \pm 0.1 \% \mathrm{ID} / \mathrm{g})$. A similar pattern was observed in background brain tissue, where uptake was $1.9 \pm 0.1 \% \mathrm{ID} / \mathrm{g}$ for ${ }^{18} \mathrm{~F}$-fluorothymidine, compared with $0.05 \pm 0.01 \% \mathrm{ID} / \mathrm{g}$ for ${ }^{68} \mathrm{Ga}-\mathrm{NOTA}-\mathrm{AE} 105$ and 0.11 $\pm 0.02 \% \mathrm{ID} / \mathrm{g}$ for ${ }^{64} \mathrm{Cu}-\mathrm{NOTA}-\mathrm{AE} 105$. The result was a significantly higher tumor-to-background ratio for both ${ }^{68} \mathrm{Ga}-\mathrm{NOTA}-\mathrm{AE} 105$ (7.6 \pm 2.1, $P<0.05)$ and ${ }^{64}$ Cu-NOTA-AE105 $(10.6 \pm 2.3, P<0.01)$ than for ${ }^{18}$ F-FET PET $(1.8 \pm 0.3)$. Autoradiography of brain slides confirmed that the accumulation of ${ }^{64} \mathrm{Cu}-\mathrm{NOTA}-\mathrm{AE} 105$ corresponded well with uPAR-positive cancer cells. Conclusion: On the basis of our translational study, UPAR PET may be a highly promising imaging biomarker for glioblastoma. Further clinical exploration of UPAR PET in glioblastoma is therefore justified.
\end{abstract}

Received Jun. 1, 2015; revision accepted Aug. 26, 2015.

For correspondence contact: Andreas Kjaer, Department of Clinical Physiology, Nuclear Medicine, and PET, Rigshospitalet-4012, Blegdamsvej 9, 2100 Copenhagen Ø, Denmark.

E-mail: akjaer@sund.ku.dk

Published online Oct. 1, 2015.

COPYRIGHT (c) 2016 by the Society of Nuclear Medicine and Molecular Imaging, Inc.
Key Words: PET/CT; glioblastoma; PET; survival; translational; urokinase-type

J Nucl Med 2016; 57:272-278

DOI: $10.2967 /$ jnumed.115.161703

$\mathbf{G}$ lioblastoma is the most common primary malignancy of the central nervous system in adults, with more than 10,000 new cases diagnosed annually in the United States $(1,2)$. It is a locally aggressive brain tumor with poor prognosis, and the median survival is limited to about 15 mo from the time of diagnosis (3). One area of focus for improving this poor prognosis is development of noninvasive molecular imaging techniques for accurate tumor detection, grading, risk stratification, treatment monitoring, and recurrence detection (4). ${ }^{18}$ F-FDG still remains the most used PET ligand for brain tumor imaging worldwide, comprising more than $90 \%$ of all PET imaging studies despite having several limitations (5). To increase specificity, sensitivity, and diagnostic accuracy, several imaging ligands for brain tumors have been developed during the last decade. Of these, PET ligands based on nucleosides, amino acid analogs, and ligands interacting with oxidative metabolism, fatty acid metabolism, and hypoxia seem to be the most promising $(5,6)$. In a clinical setting, ${ }^{18} \mathrm{~F}$-fluorothymidine $(7,8), O-\left(2-{ }^{18} \mathrm{~F}\right.$-fluoroethyl)-L-tyrosine $\left({ }^{18} \mathrm{~F}-\mathrm{FET}\right)(4,9,10)$, and ${ }^{18} \mathrm{~F}-$ fluoromisonidazole $(11,12)$ have been investigated with mixed results. Therefore, a method for optimal noninvasive imaging of brain tumors and risk stratification is still lacking.

Urokinase-type plasminogen activator receptor (uPAR) has been reported as a promising imaging target in several cancer types $(13,14)$. uPAR is an extracellular receptor, and expression of uPAR has been found to be elevated in several types of cancer and to correlate with poor prognosis (15-17). In glioblastoma, uPAR expression has been reported to be elevated and to correlate with parenchymal invasion, that is, aggressiveness (18-20). Further, a recent study has shown evidence of a direct link between upregulation of the urokinase-type plasminogen activator-uPAR-extracellular signal-regulated kinase $1 / 2$ pathway and sensitivity toward smallmolecule tyrosine kinase inhibitors for the epidermal growth factor receptor (21). Together, these make uPAR a highly promising imaging target for gliomas, with the potential for diagnosis and risk stratification and for use as a tool to identify patients sensitive toward epidermal growth factor receptor inhibitors.

In our laboratory, we have developed and characterized several uPAR PET ligands (22-25), all based on a small uPAR-antagonist 
linear peptide denoted AE105 (26). Previous in vivo characterization studies of these uPAR PET ligands have been conducted on murine xenograft models of human cancer in which tumor cells have been inoculated subcutaneously. The advantages of these models are high throughput and easy application. However, several studies have documented limitations using these models, especially with regard to clinical relevance, because of the limited similarity between in situ tumor cell physiology and immortal cancer cell lines (27). There is consensus that when human cancer cells are inoculated in the mouse organ of human origin (orthotopic), the clinical situation is modeled more closely.

To investigate the potential of UPAR PET imaging in brain tumors, we generated two new uPAR PET ligands $\left({ }^{64} \mathrm{Cu}-\mathrm{NOTA}-\mathrm{AE} 105\right.$ and ${ }^{68}$ Ga-NOTA-AE105) and examined their in vivo performance in a nude mouse orthotopic brain tumor model using an in-housedeveloped patient-derived neurosphere glioblastoma culture. Besides UPAR PET, ${ }^{18} \mathrm{~F}$-FET PET and MRI were also performed for comparison because ${ }^{18}$ F-FET PET has been implemented in the evaluation of brain tumors at several European institutions, including Rigshospitalet. Quantitative real-time polymerase chain reaction analysis of UPAR expression from biopsy samples of 19 patients diagnosed with glioblastoma was also included to investigate the association between UPAR expression and prognosis.

\section{MATERIALS AND METHODS}

\section{Ethics Statement}

This study was performed according to the Declaration of Helsinki and Danish legislation. Permission to collect and use patient data and material was granted by the Danish Data Protection Agency (2006-416979) and the ethical committee for the Capital Region of Denmark (H-C-2008-095 and KF-01-327718). Animal care and experimental procedures were performed under the approval of the Danish Animal Welfare Council.

\section{Patient Material}

The patient material consisted of tumor specimens obtained during primary surgery at Rigshospitalet from 19 randomly chosen patients diagnosed with primary glioblastoma. The 19 patients included 10 men and 9 women, with a mean age of 54.7 y (range, 34-67 y) and an Eastern Cooperative Oncology Group performance status of $0(n=13), 1(n=2)$, or $2(n=3)$ (data were missing for 1 patient). After primary surgery, 18 of the 19 patients received concomitant radiation and temozolomide therapy followed by up to 6 courses of adjuvant temozolomide therapy. Of these patients, 13 received corticosteroid therapy at treatment initiation. Further, at tumor progression, 10 of the patients underwent secondary operation, whereas 11 received relapse therapy with combined bevacizumab and irinotecan. Detailed descriptions of the treatments have previously been published elsewhere (1), and patient demographics are shown in Table 1.

\section{Quantitative Real-Time Polymerase Chain Reaction}

Quantitative real-time polymerase chain reaction analysis of relative UPAR expression was performed on RNA from all 19 glioblastoma tumor samples and from U937 and HEK 293 cells, which served as assay controls because they previously were found to have relatively high and low uPAR expression, respectively (28). RNA from the glioblastoma patient tumors was isolated using TRIzol reagent (Life Technologies) and Tissue Lyser (Qiagen) before RNA purification with the RNeasy Mini KIT (Qiagen) according to manufacturer instructions. RNA from U937 and HEK 293 cells was extracted from cell pellets using QIA shredder columns and the RNeasy Mini Kit (both from Qiagen). All RNA samples were DNase-treated using the RNaseFree DNase Set (Qiagen). cDNA was synthesized and then treated with
RNase $\mathrm{H}$ according to the manufacturer's protocol using the SuperScript III Platinum 2-step quantitative real-time polymerase chain reaction kit with SYBR Green (Life Technologies), which was also used for the subsequent quantitative real-time polymerase chain reaction. The $\Delta \Delta \mathrm{Ct}$ method was used to calculate relative gene expression. The specific primers and cycling conditions for UPAR were the same as previously described (20). Data were normalized to the expression of 3 housekeeping genes (TOP1, CYC1, and EIF4A2) (PrimerDesign), for which the cycling conditions were $95^{\circ} \mathrm{C}$ for $15 \mathrm{~s}$ and $60^{\circ} \mathrm{C}$ for $60 \mathrm{~s}$ for 50 cycles, with initial melting at $95^{\circ} \mathrm{C}$ for $2 \mathrm{~min}$.

\section{Radiochemistry}

NOTA-AE105 was purchased from ABX GmBH (Advanced Biochemical Compounds). ${ }^{64} \mathrm{Cu}$ and ${ }^{68} \mathrm{Ga}$ were produced as previously described in detail $(24,25)$. NOTA-AE105 was radiolabeled with ${ }^{64} \mathrm{Cu}$ by adding ${ }^{64} \mathrm{CuCl}_{2}(\sim 150 \mathrm{MBq})$ to a vial containing $500 \mu \mathrm{L}$ of $0.1 \mathrm{M}$ ammonium acetate buffer (pH 5.5) and NOTA-AE105 (2-20 nmol). The reaction mixture was left at room temperature for $10 \mathrm{~min}$; after purification (Sep-Pak C18 Light; Waters), the product was more than $97 \%$ pure. The amount of unlabeled ${ }^{64} \mathrm{Cu}$ in the product was less than $1 \%$, as demonstrated by radio-high-performance liquid chromatography. ${ }^{68} \mathrm{Ga}$ labeling was performed using the fractionated method. The ${ }^{68} \mathrm{Ge} /{ }^{68} \mathrm{Ga}$ generator was eluted with $6 \mathrm{~mL}$ of $0.1 \mathrm{M} \mathrm{HCl}$. Approximately $80 \%$ of the entire activity ( $1 \mathrm{~mL}, 450-500 \mathrm{MBq})$ was transferred to a vial containing 2-20 nmol of NOTA-AE105 and $1 \mathrm{~mL}$ of $0.7 \mathrm{M} \mathrm{NaOAc}$ buffer (pH 5.2). The reaction mixture was left at $60^{\circ} \mathrm{C}$ for $10 \mathrm{~min}$, and the mixture was purified by $\mathrm{C} 18$ Light Sep-Pak, resulting in purity above $95 \% .{ }^{18} \mathrm{~F}-\mathrm{FET}$ was synthesized using (2S)-O-(2-tosyloxyethyl)- $\mathrm{N}$-trityl-L-tyrosine-tertbutyl ester as precursor on a TracerLab MX (GE Healthcare). All reagents and FET cassettes were purchased from $\mathrm{ABX} \mathrm{GmBH}$. For analysis, a highperformance liquid chromatograph (Ultimate 3000; Dionex) was used with a $2.6-\mu \mathrm{m}, 100-\AA, 50 \times 4.6 \mathrm{~mm} \mathrm{C18}$ column (Kinetex). The mobile phases for ${ }^{64} \mathrm{Cu}-\mathrm{NOTA}-\mathrm{AE} 105$ and ${ }^{68} \mathrm{Ga}-\mathrm{NOTA}-\mathrm{AE} 105$ were as follows: eluent $\mathrm{A}: 10 \% \mathrm{MeCN}$ in $\mathrm{H}_{2} \mathrm{O}$ with $0.1 \%$ trifluoroacetic acid; eluent $\mathrm{B}$ : $10 \% \mathrm{H}_{2} \mathrm{O}$ in $\mathrm{MeCN}$ with $0.1 \%$ trifluoroacetic acid. The mobile phase for ${ }^{18} \mathrm{~F}-\mathrm{FET}$ was $98 \% 20 \mathrm{mM}$ acetate buffer, $\mathrm{pH} 4.75$, with $2 \% \mathrm{MeCN}$.

\section{Orthotopic Brain Tumor Model}

A glioblastoma CPH048p6 neurosphere cell culture having a stable expression of luciferase was used to establish an orthotopic glioblastoma model. This culture had previously been established from patient 19 (CPH48) (Table 1). Establishment, culturing, and luciferase transduction of this cell culture have previously been described (2). The orthotopic glioblastoma xenograft model was generated as recently described in detail $(28,29)$. In brief, a longitudinal incision was made in the scalp, exposing the calvarium. Using a microdrill, a burr hole was created in the skull $1.5 \mathrm{~mm}$ to the right of the sutura sagittalis and $0.5 \mathrm{~mm}$ posterior to the bregma. A $10-\mu \mathrm{L}$ cell suspension $(100,000$ cells) was injected at a depth of $2-2.5 \mathrm{~mm}$ at a rate of $60 \mathrm{~nL} / \mathrm{s}$ using a $100-\mu \mathrm{L}$ syringe with a 25 -gauge needle (SGE100RN; World Precision Instruments) placed in a microinfusion pump (Micro4 controller and MicroSyringe pump controller [World Precision Instruments] and KOPF model 1770-C [Better Hospital Equipment Corp.]). The animals were housed in a climate-controlled room with a 12-h light:12-h dark cycle. They had free access to food and water during housing.

\section{Bioluminescence Imaging}

For bioluminescence imaging, the mice were injected intraperitoneally with D-luciferin ( $150 \mathrm{mg} / \mathrm{kg}$ of body weight $)$ according to the scheme in Figure 2. Images were acquired using a Xenogen IVIS 100 (Caliper Life Sciences) 10 min after injection of D-luciferin.

\section{Small-Animal PET/CT Imaging}

Each mouse received a tail-vein injection of ${ }^{18} \mathrm{~F}-\mathrm{FET}(10 \mathrm{MBq}, n=3)$, ${ }^{64} \mathrm{Cu}-\mathrm{NOTA}-\mathrm{AE} 105$ (6 MBq, $n=3$ ), or ${ }^{68} \mathrm{Ga}-\mathrm{NOTA}-\mathrm{AE} 105$ (6 MBq, 
TABLE 1

Patient Characteristics and uPAR mRNA Expression Relative to Expression in HEK293 Cells

\begin{tabular}{|c|c|c|c|c|c|c|c|c|c|c|c|c|}
\hline $\begin{array}{c}\text { Patient } \\
\text { no. }\end{array}$ & Sex & $\begin{array}{c}\text { Age at } \\
\text { diagnosis (y) }\end{array}$ & $\begin{array}{l}\text { WHO } \\
\text { grade }\end{array}$ & $\begin{array}{c}\text { ECOG } \\
\text { performance } \\
\text { status }\end{array}$ & $\begin{array}{l}\text { Resection } \\
\text { at primary } \\
\text { operation* }\end{array}$ & $\begin{array}{l}\text { Primary } \\
\text { RT/TMZ } \\
\text { therapy }\end{array}$ & $\begin{array}{c}\text { TMZ } \\
\text { series }\end{array}$ & $\begin{array}{c}\text { Best } \\
\text { response }\end{array}$ & $\begin{array}{l}\text { Corticosteroids } \\
\text { at start of } \\
\text { RT/TMZ }\end{array}$ & $\begin{array}{c}\text { Bevacizumab/ } \\
\text { irinotecan }\end{array}$ & Reoperation & $\begin{array}{c}\text { UPAR mRNA } \\
\text { expression }\end{array}$ \\
\hline $1^{\dagger}$ & $\mathrm{F}$ & 53 & IV & - & - & - & - & - & - & - & - & 4.57 \\
\hline $2^{\dagger}$ & $M$ & 40 & IV & 0 & Partial & Yes & 0 & PD & Yes & No & Yes & 20.62 \\
\hline 3 & $\mathrm{M}$ & 40 & IV & 0 & Gross total & Yes & 1 & PD & Yes & Yes & Yes & 1.54 \\
\hline $4^{\dagger}$ & $M$ & 63 & IV & 2 & Gross total & Yes & 1 & PD & Yes & No & No & 4.71 \\
\hline 5 & $\mathrm{M}$ & 63 & IV & 0 & Partial & Yes & 5 & $\mathrm{SD}$ & Yes & Yes & No & 1.88 \\
\hline 6 & $\mathrm{~F}$ & 34 & IV & 0 & Gross total & Yes & 6 & $\mathrm{SD}$ & No & Yes & No & 0.35 \\
\hline 7 & $\mathrm{M}$ & 59 & IV & 0 & Gross total & Yes & 5 & $\mathrm{SD}$ & Yes & Yes & Yes & 2.49 \\
\hline 8 & $\mathrm{M}$ & 40 & IV & 0 & Gross total & Yes & 0 & PD & Yes & Yes & Yes & 2.21 \\
\hline 9 & $\mathrm{~F}$ & 54 & IV & 2 & Partial & Yes & 2 & PD & No & No & Yes & 1.23 \\
\hline $10^{\dagger}$ & $M$ & 64 & IV & 0 & Gross total & Yes & 5 & PR & No & No & Yes & 6.54 \\
\hline 11 & $\mathrm{~F}$ & 58 & IV & 0 & Partial & Yes & 2 & PD & Yes & No & No & 1.06 \\
\hline $12^{\dagger}$ & $\mathrm{M}$ & 63 & IV & 1 & Partial & Yes & 0 & PD & Yes & No & No & 3.78 \\
\hline 13 & $\mathrm{~F}$ & 60 & IV & 0 & Gross total & Yes & 2 & PD & Yes & Yes & No & 2.15 \\
\hline 14 & $\mathrm{~F}$ & 56 & IV & 0 & Partial & Yes & 5 & $\mathrm{SD}$ & Yes & Yes & Yes & 2.39 \\
\hline 15 & $\mathrm{M}$ & 64 & IV & 0 & Partial & Yes & 6 & PR & No & Yes & Yes & 2.04 \\
\hline $16^{\dagger}$ & $\mathrm{F}$ & 67 & IV & 1 & Gross total & Yes & 3 & $\mathrm{SD}$ & Yes & No & Yes & 4.75 \\
\hline $17^{\dagger}$ & $\mathrm{F}$ & 61 & IV & 0 & Gross total & Yes & 2 & PD & Yes & Yes & No & 14.41 \\
\hline 18 & $\mathrm{M}$ & 47 & IV & 0 & Gross total & Yes & 2 & PD & No & Yes & Yes & 1.63 \\
\hline $19^{\dagger \ddagger}$ & $\mathrm{F}$ & 54 & IV & 0 & Partial & Yes & 2 & PD & Yes & Yes & No & 5.63 \\
\hline
\end{tabular}

${ }^{*}$ Extent was based on assessment by surgeon.

${ }^{\dagger}$ From high-uPAR group (>3).

${ }^{\ddagger} \mathrm{CPH} 048$.

WHO = World Health Organization; ECOG = Eastern Cooperative Oncology Group; RT = radiation therapy; TMZ = temozolomide; $\mathrm{mRNA}=$ messenger RNA; $\mathrm{PD}=$ progressive disease; $\mathrm{SD}=$ stable disease; $\mathrm{PR}=$ partial response.

$n=3$ ) according to the scheme in Figure 2. PET scans were acquired with a microPET Focus 120 scanner (Siemens Medical Solutions). The energy window of the emission scans was set to $350-605 \mathrm{keV}$ with a time resolution of $6 \mathrm{~ns}$. The acquired emission dataset was automatically stored in list mode. Each mouse was scanned $1 \mathrm{~h}$ after injection $\left({ }^{64} \mathrm{Cu}-\mathrm{NOTA}-\mathrm{AE} 105\right.$ and $\left.{ }^{68} \mathrm{Ga}-\mathrm{NOTA}-\mathrm{AE} 105\right)$ or $0.5 \mathrm{~h}$ after injection $\left({ }^{18} \mathrm{~F}-\mathrm{FET}\right)$, with a 10 -min static PET scan being followed by a CT scan. CT data were acquired with a microCAT II tomograph (Siemens Medical Solutions). The x-ray tube with a 0.5 -mm aluminum filter was set at $80 \mathrm{kVp}$, a tube current of $500 \mu \mathrm{A}$, and an exposure time of $700 \mathrm{~ms}$ per projection. The voxel size was $0.095 \times 0.095 \times 0.095 \mathrm{~mm}$. During the scan, the animals were anesthetized using $2 \%$ isoflurane. All list-mode data were postprocessed into $128 \times 128 \times 32$ sinograms using a 3-dimensional maximum a priori algorithm and into $256 \times 256 \times 95$ matrices with a isometric voxel size of $0.43 \mathrm{~mm}^{3}$. The resolution of the PET scanner was $1.5 \mathrm{~mm}$ at the center of the field of view and $1.8 \mathrm{~mm}$ at $38 \mathrm{~mm}$ off-center using a 3-dimensional maximum a priori algorithm. All results were analyzed using Inveon software (Siemens Medical Solutions), and tracer uptake was expressed as percentage injected dose (\%ID) per gram of tissue.

\section{MRI}

MRI experiments were performed on a Biospec 7.0 (Bruker BioSpin). A TurboRare T2-weighted protocol was used to generate transverse and coronal images. Eight transverse slices and 12 coronal slices $0.5 \mathrm{~mm}$ thick were acquired using a repetition time of $2,500 \mathrm{~ms}$ and an echo time of $33 \mathrm{~ms}$. A $20 \times 20 \mathrm{~mm}$ field of view was sampled into a $256 \times 256 \mathrm{~mm}$ matrix, resulting in a spatial resolution of 0.078 .
The MR images were then transferred in DICOM format into the Inveon software for analysis.

\section{Autoradiography}

The distribution pattern of ${ }^{64} \mathrm{Cu}-\mathrm{NOTA}-\mathrm{AE} 105$ in resected tumors was determined by exposing tumor sections to phosphor imaging screens for $24 \mathrm{~h}$. The sections were interpreted using a phosphor imaging system (Cyclone Plus; Perkin Elmer) to form photostimulated luminescence images of ${ }^{64} \mathrm{Cu}-\mathrm{NOTA}-\mathrm{AE} 105$ microregional distribution. Tumor slides were subsequently frozen and stored at $-80^{\circ} \mathrm{C}$ degrees until immunohistochemical analysis.

\section{Immunohistochemistry}

Standard hematoxylin and eosin staining was performed together with uPAR staining on freshly frozen slides. For uPAR staining, recombinant human uPAR antibody R2 was used as previously described $(30,31)$. uPAR immunostaining was performed as previously described (32), with minor modifications. Endogenous peroxidase activity was blocked by incubation in a $1 \%(\mathrm{v} / \mathrm{v})$ hydrogen peroxide-water solution for $15 \mathrm{~min}$. The primary rabbit polyclonal antibody against human UPAR (33) was diluted in antibody diluent (S3022; Dako) and incubated overnight in Shandon racks (Thermo Fisher Scientific) at a concentration of $1.8 \mu \mathrm{g} / \mathrm{mL}$. Subsequently, the primary antibodies were detected with EnVision reagent (Dako), with antirabbit IgG horseradish peroxidaseconjugated polymers (K4003; Dako). The reactions were visualized by incubating the sections with NovaRED (Vector Laboratories) according to the manufacturer's instructions and counterstaining with Mayer hematoxylin. 


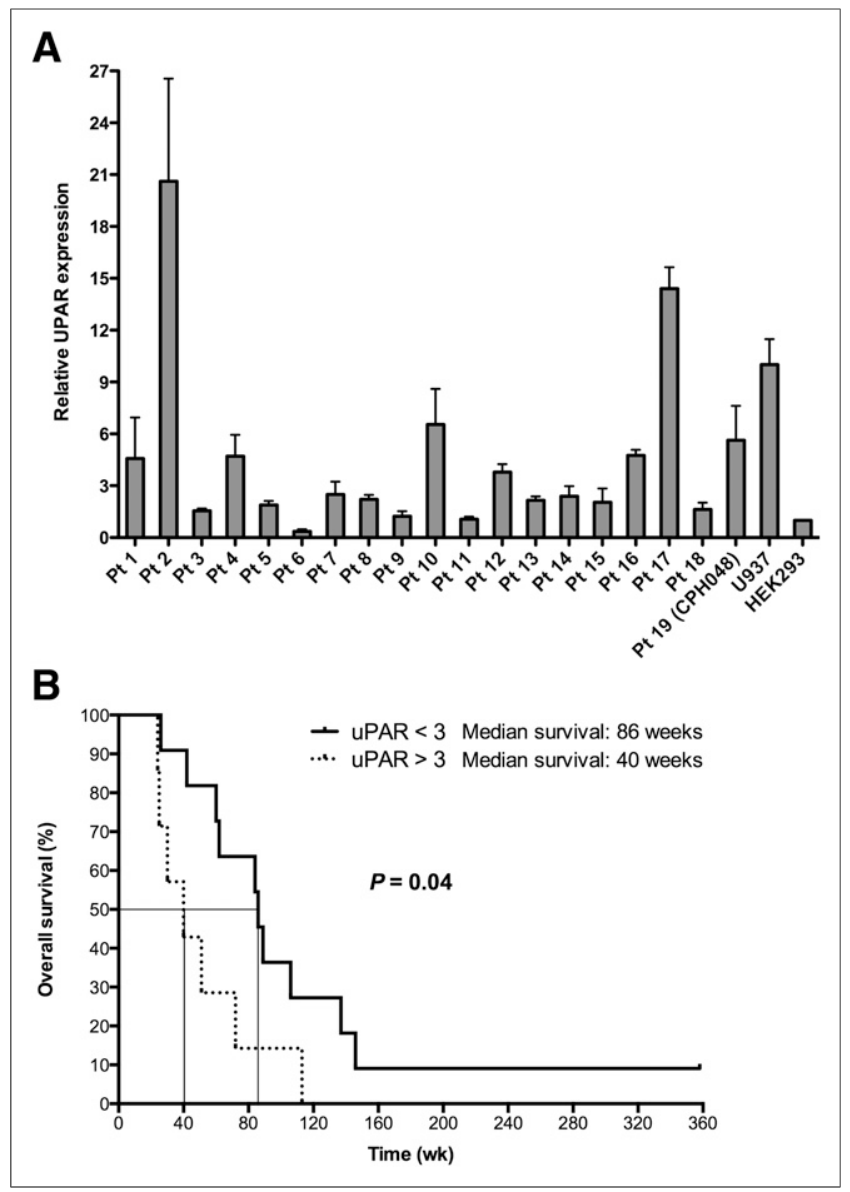

FIGURE 1. (A) Relative UPAR messenger RNA levels in 19 patients diagnosed with glioblastoma compared with HEK293 kidney cells. Included in the analysis is human leukemic monocyte lymphoma cell line U937, previously shown to be highly positive for UPAR. Cancer cells from patient 19 (CPH048) were used to establish cell culture for generation of orthotopic glioblastoma mouse model in this study. (B) Significantly shorter overall survival $(P=0.04)$ in 19 patients diagnosed with glioblastoma stratified according to uPAR expression in tumor using Cox regression analysis.

\section{Statistical Analysis}

Statistical analyses were performed using Prism, version 6.0 (GraphPad Software, Inc.) for Mac OS X (Apple). Treatment groups were compared using 1-way ANOVA. Data are presented as mean \pm SEM if not stated otherwise. A $P$ level of less than 0.05 was considered statistically significant. Survival analysis was performed using the Kaplan-Meier method and the log-rank test.

\section{RESULTS}

\section{uPAR Gene Expression in Glioblastoma Patients}

Tumor samples from 19 patients diagnosed with glioblastoma were examined for uPAR messenger RNA expression, and all samples were positive (Table 1; Fig. 1A). In addition, when compared with human embryonic kidney 293 cells, uPAR expression was higher in 18 of 19 glioblastoma patients. In most (13/19), expression of UPAR was more than 2-fold higher, with 3 patients having an increase of more than 10fold, thus confirming the potential of uPAR as a promising target for imaging of glioblastoma. Survival analysis, using a 3-fold increased uPAR as the cutoff, revealed a significantly shorter overall survival in patients with high uPAR expression $(P=0.04)$ (Fig. 1B). No differences in age at diagnosis, sex, performance status, extent of primary operation, corticosteroid use, number of temozolomide series received, or reoperation were found between the two groups. In contrast, there was a tendency toward a correlation between UPAR expression levels and bevacizumab/irinotecan relapse therapy $(P=0.05)$ (Table 1$)$. Nine of 11 patients in the low-uPAR group (uPAR $<3$ ), for example, received additional treatment with bevacizumab/irinotecan, whereas this therapy was given to only 2 of 7 patients in the high-uPAR group.

\section{Orthotopic Glioblastoma Xenograft Model}

Cultured glioblastoma neurospheres from patient 19 (CPH048) were used to establish orthotopic glioblastoma xenografts as illustrated in Figure 2A. Tumor take and growth were monitored using bioluminescence imaging, and tumor lesions could be identified as early as $3 \mathrm{wk}$ after inoculation of the neurospheres (Fig. 2B).

\section{Radiochemistry}

Two uPAR PET ligands were produced in this study for, what was to our knowledge, the first time. Labeling of NOTA-AE105 with ${ }^{68} \mathrm{Ga}$ and ${ }^{64} \mathrm{Cu}$ was investigated using different amounts of precursor to increase the specific activity. A high yield was observed for both ligands using 2-20 nmol of NOTA-AE105 (Fig. 3A). A labeling yield of $70 \%-80 \%(2 \mathrm{nmol})$ to $90 \%-95 \%$ (20 nmol) was found for both ligands. ${ }^{64} \mathrm{Cu}-\mathrm{NOTA}-\mathrm{AE} 105 \mathrm{had}$ a higher yield than ${ }^{68} \mathrm{Ga}$-NOTA-AE105 at all levels investigated. For all in vivo PET studies, $2 \mathrm{nmol}$ of precursor were used, resulting in a specific activity of approximately $20 \mathrm{GBq} / \mu \mathrm{mol}$ for both ligands. After SepPak purification, the radiochemical purity was more than $98 \%$ for ${ }^{64} \mathrm{Cu}-\mathrm{NOTA}-\mathrm{AE} 105$ (Fig. 3B) and more than $97 \%$ for ${ }^{68} \mathrm{Ga}-\mathrm{NOTA}-$ AE105 (Fig. 3C). The final product was diluted in phosphatebuffered saline ready for injection.

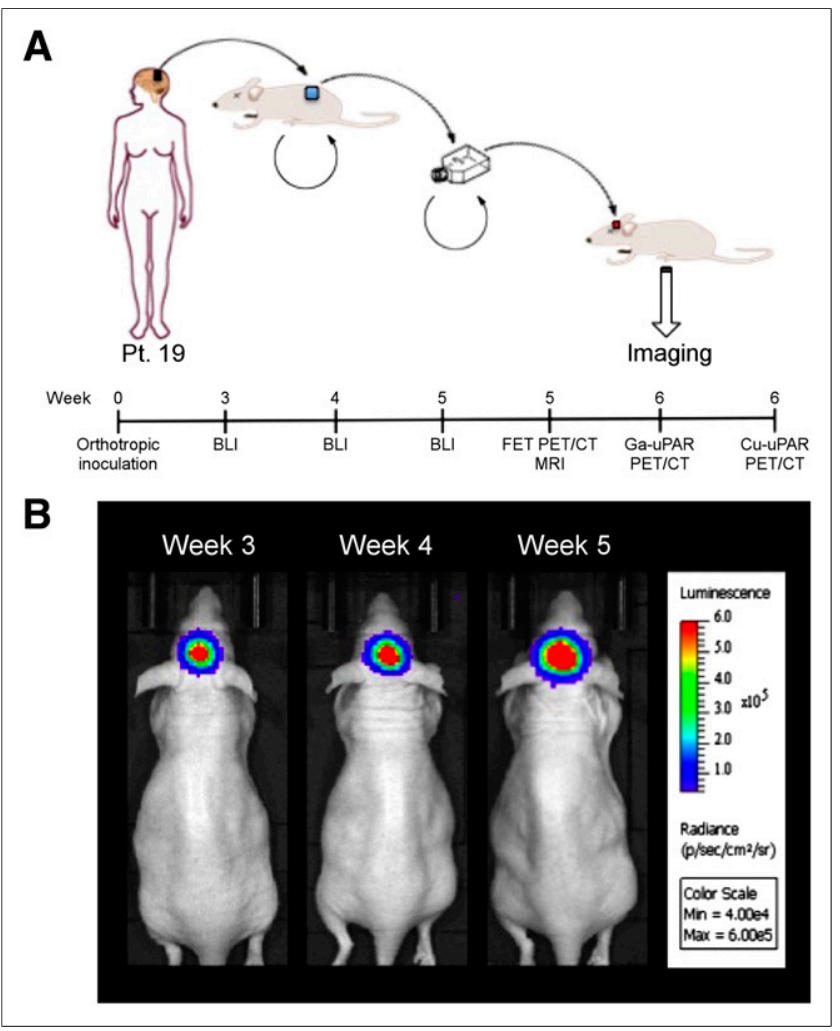

FIGURE 2. (A) Schematic of procedure for generating orthotopic glioblastoma mouse model. (B) Weekly bioluminescence imaging (BLI) to monitor tumor growth. 


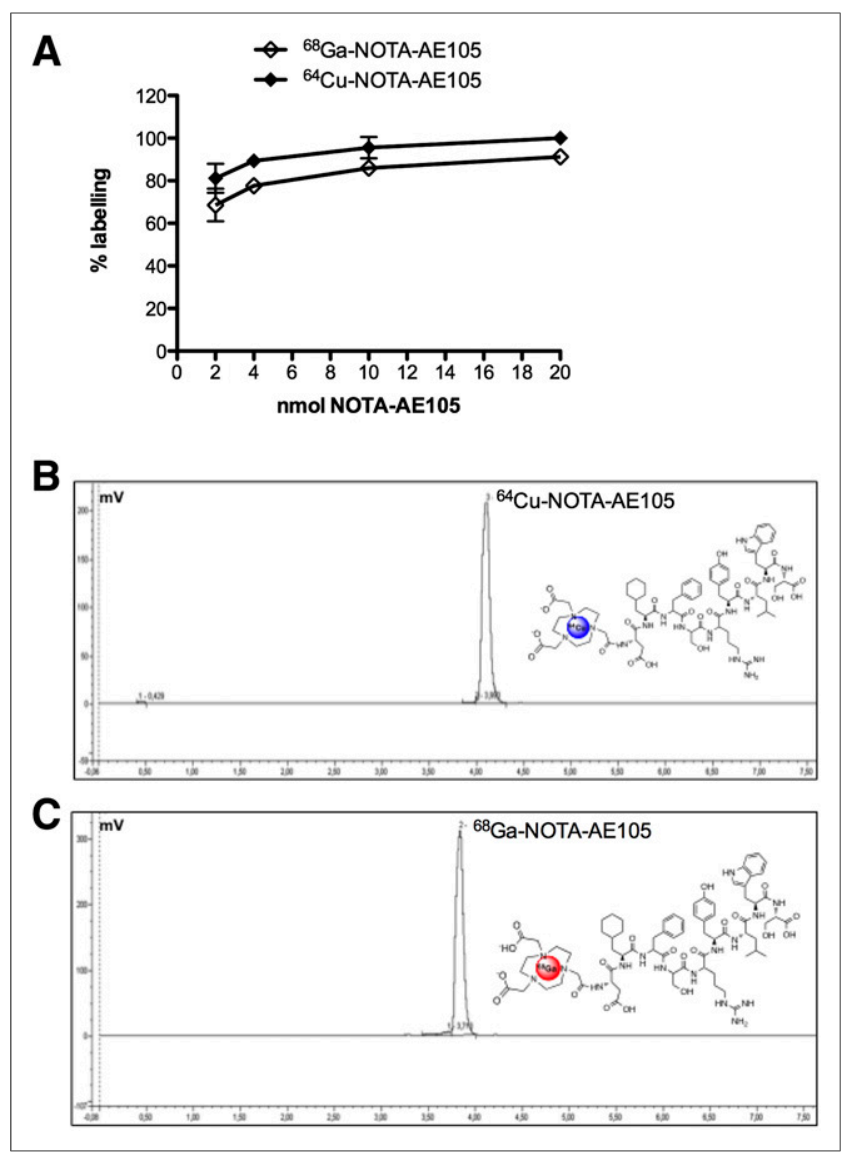

FIGURE 3. (A) Labeling efficiency with ${ }^{68} \mathrm{Ga}$ and ${ }^{64} \mathrm{Cu}$ using different amounts of NOTA-AE105 precursor (mean \pm SD, $n=3$ ). (B and C) Chemical structures of ${ }^{64} \mathrm{Cu}-\mathrm{NOTA}-\mathrm{AE} 105$ (B) and ${ }^{68} \mathrm{Ga}-\mathrm{NOTA}-\mathrm{AE} 105$ (C) together with representative high-performance liquid chromatogram of final product after Sep-Pak purification using 2 nmol of precursor.

\section{PET/CT and MRI}

UPAR PET/CT and MRI were conducted 5-6 wk after inoculation of the xenografts, with bioluminescence imaging confirming the orthotopic glioblastoma tumors. High image contrast, resulting in clear tumor delineation, was found for both ${ }^{68} \mathrm{Ga}$-NOTA-AE105 and ${ }^{64} \mathrm{Cu}-\mathrm{NOTA}-\mathrm{AE} 105$ (Fig. 4). Coregistration with MRI confirmed the tumors and corresponded with the UPAR PET hot spot. Additionally, ${ }^{18}$ F-FET PET/CT was performed on the same cohort of mice. In both tumor and background brain tissue, an increased level of absolute ${ }^{18} \mathrm{~F}$-FET uptake, in comparison with ${ }^{68} \mathrm{Ga}-\mathrm{NOTA}-\mathrm{AE} 105$ and ${ }^{64} \mathrm{Cu}-$ NOTA-AE105 uptake, was found (Fig. 4). To investigate the specificity of uPAR PET uptake in tumors, uPAR PET/CT, ${ }^{18}$ F-FET PET, and MRI were performed on a cohort of mice with no tumor cells inoculated (denoted normal mouse in Fig. 4). Similarly low uptake in normal brain tissue was observed for all 3 PET ligands in all mice, both tumor-inoculated and normal. This finding indicates that accumulation of the UPAR PET ligands in the brain is tumor-mediated.

Quantitative analysis of all PET/CT images found a significantly higher tumor-to-background (T/B) ratio for both ${ }^{64} \mathrm{Cu}-\mathrm{NOTA}-\mathrm{AE} 105$ $(P<0.01)$ (Fig. 5A) and ${ }^{68}$ Ga-NOTA-AE105 $(P<0.001)$ (Fig. 5B), thus resulting in high-contrast images. Tumor uptake of ${ }^{64} \mathrm{Cu}-\mathrm{NOTA}-$ AE105 was $1.2 \pm 0.4 \% \mathrm{ID} / \mathrm{g}$, with background brain uptake of $0.11 \pm 0.02 \% \mathrm{ID} / \mathrm{g}$ in tumor mouse brains and $0.07 \pm 0.01 \% \mathrm{ID} / \mathrm{g}$ in normal mouse brains without tumor (Fig. 5A). The tumor uptake was $0.4 \pm 0.1 \% \mathrm{ID} / \mathrm{g}$ for ${ }^{68} \mathrm{Ga}-\mathrm{NOTA}-\mathrm{AE} 105$, whereas similarly low background uptake was found in tumor mouse brains $(0.05 \pm 0.01$ $\% \mathrm{ID} / \mathrm{g})$ and normal mouse brains $(0.06 \pm 0.02 \% \mathrm{ID} / \mathrm{g})$ (Fig. 5B). Higher absolute tumor uptake was seen for ${ }^{18} \mathrm{~F}$-FET PET, at $3.5 \pm 0.8 \% \mathrm{ID} / \mathrm{g}$ (Fig. 5C). However, the background uptake in both tumor mouse brains and normal mouse brains was also higher, at $1.9 \pm 0.1 \% \mathrm{ID} / \mathrm{g}$ and $1.2 \pm 0.1 \% \mathrm{ID} / \mathrm{g}$, respectively, resulting in a significantly higher T/B ratio for both ${ }^{68} \mathrm{Ga}-\mathrm{NOTA}-\mathrm{AE} 105$ $(7.6 \pm 2.1, P<0.05)$ and ${ }^{64} \mathrm{Cu}-\mathrm{NOTA}-\mathrm{AE} 105(10.6 \pm 2.3$, $P<0.01)$ than for ${ }^{18} \mathrm{~F}$-FET PET $(1.8 \pm 0.3)$ (Fig. 5D). ${ }^{68} \mathrm{Ga}-$ NOTA-AE105 and ${ }^{64} \mathrm{Cu}$-NOTA-AE105 did not significantly differ.

\section{Ex Vivo Correlation Between UPAR PET and uPAR Expression}

Hematoxylin and eosin staining confirmed that tumor cells were primarily in the ventricle of the brain (Fig. 6A) and corresponded well with uPAR-positive cancer cells (Fig. 6B). Autoradiography of the same slide confirmed that the accumulation of ${ }^{64} \mathrm{Cu}-\mathrm{NOTA}$ AE105 corresponded to uPAR-positive cancer cells (Fig. 6C), thus providing strong evidence of the specificity of the UPAR PET ligand.

\section{DISCUSSION}

Given that glioblastoma has a poor prognosis due, partly, to lack of an optimal method for diagnosis, risk stratification, and treatment monitoring, the development of novel, noninvasive molecular imaging techniques remains a clinical need. To examine whether PET tracers targeting UPAR can be of potential use here, we developed such tracers and evaluated their relevance for clinical use, in part through preclinical investigations in an orthotopic glioblastoma mouse model and in part through UPAR expression analysis in patient glioblastoma tumors.

In glioblastoma, the expression and role of uPAR have previously been investigated by others $(18,20,34,35)$. Common to all studies was the confirmation of high uPAR expression in highgrade glioma (World Health Organization grades III and IV) and low or barely detectable expression in normal brain tissues and low-grade gliomas (World Health Organization grade II). In addition, a significant correlation between increased UPAR expression and increased glioma tumor grade has been reported (18). These results are

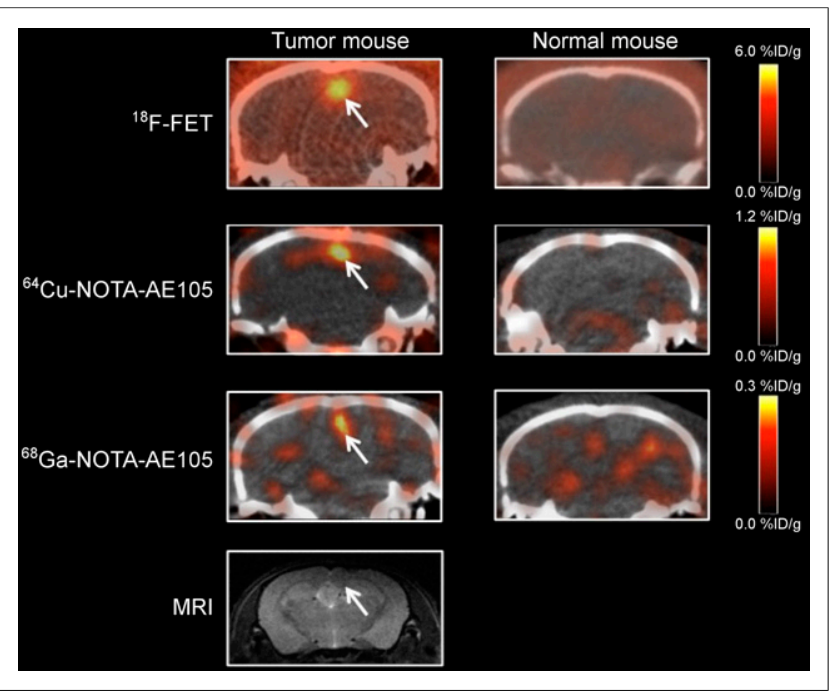

FIGURE 4. Representative coronal PET images of mouse with orthotopic patient-derived glioblastoma tumor (arrows) and of normal mouse after ${ }^{18} \mathrm{~F}-\mathrm{FET},{ }^{64} \mathrm{Cu}-\mathrm{NOTA}$-AE 105 , and ${ }^{68} \mathrm{Ga}-\mathrm{NOTA}-\mathrm{AE} 105$ injection. MR image of same mouse brain is shown at bottom. 


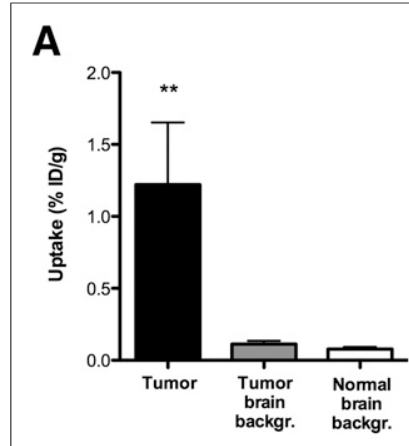

\section{B}

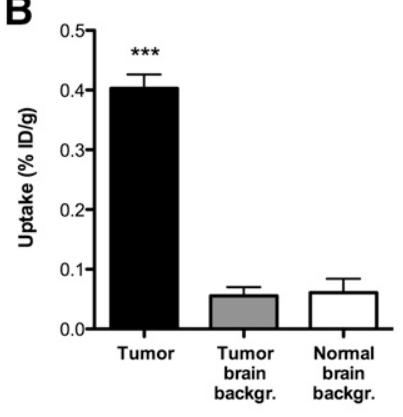

C

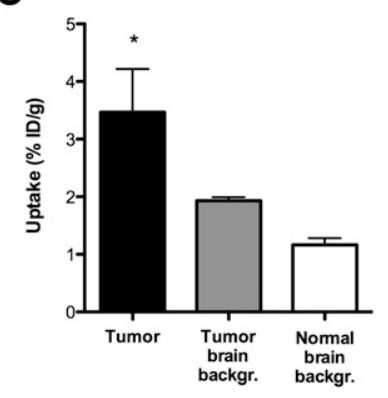

D

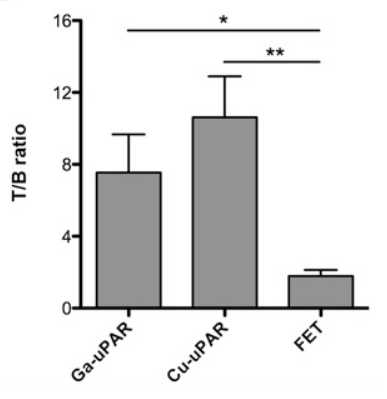

FIGURE 5. Uptake in tumor, hemisphere contralateral to tumor (tumor brain), and normal brain with no tumor (normal brain) $1 \mathrm{~h}$ after injection of ${ }^{64} \mathrm{Cu}-\mathrm{NOTA}-\mathrm{AE} 105$ (A) or ${ }^{68} \mathrm{Ga}-\mathrm{NOTA}-\mathrm{AE} 105$ (B) and $0.5 \mathrm{~h}$ after injection of ${ }^{18} \mathrm{~F}-\mathrm{FET}(\mathrm{C})$. (D) Calculated T/B ratios for all 3 PET ligands. Backgr. $=$ background.

in line with the expression analysis in our cohort of 19 patients, all of whom were diagnosed with glioblastoma. Eighteen of 19 patients had elevated uPAR expression, ranging from 2- to 10-fold compared with low-expressing reference cells. Also, to our knowledge we are now the

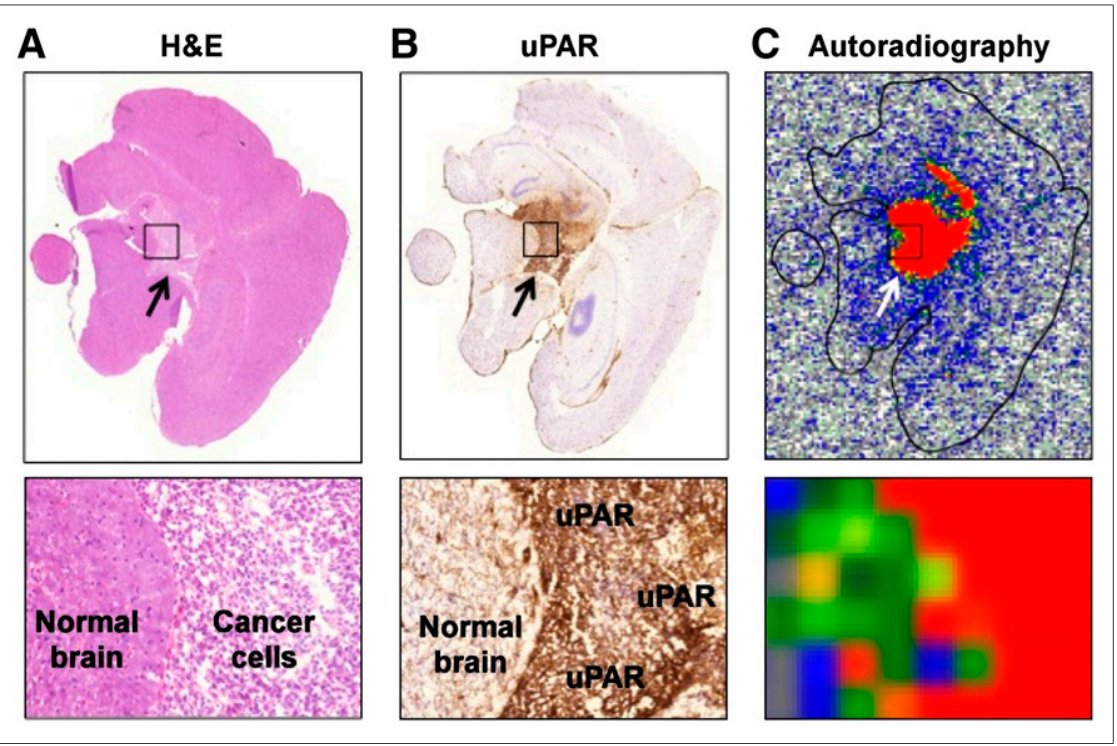

FIGURE 6. Immunohistochemistry and autoradiography of mouse brain containing tumor. Standard hematoxylin and eosin staining (A) was performed together with uPAR staining (B), and distribution pattern of ${ }^{64} \mathrm{Cu}$-NOTA-AE105 was determined using autoradiography (C). High similarity was found between human cancer cells, UPAR staining, and distribution of activity (arrows). High magnification of area within black square is shown at bottom right.

first to present data indicating that elevated UPAR expression in glioblastoma significantly correlates with overall survival. Use of bevacizumab/irinotecan relapse therapy tended to differ between the two groups $(P=0.05)$. The clinical decision to use bevacizumab/ irinotecan in only 2 of 7 patients in the high-uPAR group most likely reflects an objective assessment of the poor performance of individual patients at the time of relapse. In contrast, 9 of 11 patients in the lowuPAR group received relapse therapy, thus reflecting an overall better performance status in this group at the time of relapse. However, because of the limited number of patients in our cohort and the heterogeneity in their treatment profiles, a larger study will have to confirm our data. Given the elevated expression in glioma (especially high-grade glioma), the prognostic value, and the recently found link between upregulation of the urokinase-type plasminogen activatoruPAR-extracellular signal-regulated kinase $1 / 2$ pathway and sensitivity toward small-molecule epidermal growth factor receptor tyrosine kinase inhibitors (21), uPAR seems to be a promising target for noninvasive imaging in glioblastoma.

Orthotopic tumor models are regarded as superior to traditional subcutaneous models, as the microenvironment is important for tumor development and compound delivery (36). The use of different noninvasive imaging modalities, including PET, makes monitoring of tumor development in orthotopic models feasible. In this study, we used an in-house-established orthotopic mouse model to investigate the potential of peptide-based UPAR PET imaging in a clinically relevant model of glioblastoma. Our ${ }^{18} \mathrm{~F}$ FET PET T/B ratio $(1.8 \pm 0.3)$ was in the mid range of those reported in several clinical studies $(0.7-3.2)(4,9)$, further underlining the clinical relevance of our model.

A small difference in radiolabeling efficiency was observed between the two uPAR PET ligands (Fig. 2A), with efficiency being higher for ${ }^{64} \mathrm{Cu}-\mathrm{NOTA}-\mathrm{AE} 105$. In vivo, absolute tumor uptake was higher for ${ }^{64} \mathrm{Cu}-\mathrm{NOTA}-\mathrm{AE} 105$ than for ${ }^{68} \mathrm{Ga}-\mathrm{NOTA}-\mathrm{AE} 105$. However, the higher absolute uptake also caused higher background uptake, thus resulting in similar T/B ratios for the two ligands as shown in Figure 5D.

The high T/B ratios found for our uPAR PET ligands $(7.6 \pm 2.1$ and $10.6 \pm 2.3$ for ${ }^{68} \mathrm{Ga}-\mathrm{NOTA}-\mathrm{AE} 105$ and ${ }^{64} \mathrm{Cu}-\mathrm{NOTA}-\mathrm{AE} 105$, respectively) indicate that UPAR PET might be a promising method for tumor assessment in glioblastoma. Investigation of the potential of UPAR PET as a tool for early identification of epidermal growth factor receptor tyrosine kinase inhibitor sensitivity also seems intriguing. In addition, because of the prognostic value of UPAR expression, UPAR PET might be used for risk stratification in glioblastoma. However, future clinical studies are needed to further explore these hypotheses. Importantly, the close similarity between uPAR staining and accumulation of activity $\left({ }^{64} \mathrm{Cu}-\mathrm{NOTA}-\right.$ AE105) as shown in Figure 6 confirms the high selectivity of this uPAR-targeting peptide and is in line with our previous findings across 3 human cancer cell lines, for which there was a close correlation between tumor uptake and UPAR expression (25).

One aspect to bear in mind is the high species specificity of our uPAR-binding peptide, with binding affinity having been 
shown to be 200 -fold lower to mouse uPAR than to human uPAR (31). This species specificity could partly explain the low uptake in background brain tissue and the correspondingly high T/B ratio compared with ${ }^{18} \mathrm{~F}$-FET PET, since only mouse uPAR is expressed in normal brain tissue whereas ${ }^{18} \mathrm{~F}$-FET PET is species-independent. However, in view of results showing low or undetectable levels of uPAR in normal brain tissue (20), the T/B ratio in a clinical setting would presumably be satisfying, exemplified by the 15 -fold increased level of uPAR messenger RNA expression compared with low-grade gliomas and normal brain tissues reported by Yamamoto et al. (20). The blood-brain barrier is another important aspect when new PET tracers are evaluated for brain tumor imaging (37), and whether this factor affects our UPAR tracer remains to be elucidated.

On the basis of recently published studies on the performance of ${ }^{18} \mathrm{~F}-\mathrm{FET}$ PET in glioblastoma $(4,9)$, there seems to be a consensus that ${ }^{18}$ F-FET PET has value in defining the optimal site for biopsy. However, ${ }^{18} \mathrm{~F}$-FET PET has limited specificity for the detection of primary brain tumors (10). Because UPAR expression is primarily at the invasive edge and has prognostic value in glioma patients, UPAR PET may reveal additional information about tumor grade and be used for risk stratification in glioblastoma.

\section{CONCLUSION}

We found UPAR PET to be a promising imaging modality for glioblastoma based on preclinical data from an orthotopic glioblastoma mouse model using two new uPAR PET ligands and on human uPAR expression data from glioblastoma patient tumor samples.

\section{DISCLOSURE}

The costs of publication of this article were defrayed in part by the payment of page charges. Therefore, and solely to indicate this fact, this article is hereby marked "advertisement" in accordance with 18 USC section 1734 . No potential conflict of interest relevant to this article was reported.

\section{REFERENCES}

1. Clarke J, Butowski N, Chang S. Recent advances in therapy for glioblastoma. Arch Neurol. 2010;67:279-283.

2. Michaelsen SR, Christensen IJ, Grunnet K, et al. Clinical variables serve as prognostic factors in a model for survival from glioblastoma multiforme: an observational study of a cohort of consecutive nonselected patients from a single institution. BMC Cancer. 2013;13:402.

3. Desjardins A, Friedman HS. Neuro-oncology: glioblastoma—community adjusts to new standard of care. Nat Rev Neurol. 2012;8:244-246.

4. Rapp M, Heinzel A, Galldiks N, et al. Diagnostic performance of ${ }^{18}$ F-FET PET in newly diagnosed cerebral lesions suggestive of glioma. J Nucl Med. 2013;54:229-235.

5. Gulyás B, Halldin C. New PET radiopharmaceuticals beyond FDG for brain tumor imaging. Q J Nucl Med Mol Imaging. 2012;56:173-190.

6. Alexiou GA, Tsiouris S, Voulgaris S, Kyritsis AP, Fotopoulos AD. Glioblastoma multiforme imaging: the role of nuclear medicine. Curr Radiopharm. 2012;5:308-313.

7. Choi SJ, Kim JS, Kim JH, et al. $\left[{ }^{18} \mathrm{~F}\right] 3^{\prime}$-deoxy- $3^{\prime}$-fluorothymidine PET for the diagnosis and grading of brain tumors. Eur J Nucl Med Mol Imaging. 2005;32:653-659.

8. Idema AJ, Hoffmann AL, Boogaarts HD, et al. $3^{\prime}$-deoxy $-3^{\prime}-{ }^{18} \mathrm{~F}$-fluorothymidine PET-derived proliferative volume predicts overall survival in high-grade glioma patients. J Nucl Med. 2012;53:1904-1910.

9. Galldiks N, Stoffels G, Ruge MI, et al. Role of O-(2- ${ }^{18}$ F-fluoroethyl)-L-tyrosine PET as a diagnostic tool for detection of malignant progression in patients with low-grade glioma. J Nucl Med. 2013;54:2046-2054.

10. Hutterer M, Nowosielski M, Putzer D, et al. $\left[{ }^{18} \mathrm{~F}\right]$-fluoro-ethyl-L-tyrosine PET: a valuable diagnostic tool in neuro-oncology, but not all that glitters is glioma. Neuro-Oncol. 2013;15:341-351.

11. Spence AM, Muzi M, Swanson KR, et al. Regional hypoxia in glioblastoma multiforme quantified with $\left[{ }^{18} \mathrm{~F}\right]$ fluoromisonidazole positron emission tomography before radiotherapy: correlation with time to progression and survival. Clin Cancer Res. 2008;14:2623-2630.
12. Hirata K, Terasaka S, Shiga T, et al. ${ }^{18} \mathrm{~F}$-fluoromisonidazole positron emission tomography may differentiate glioblastoma multiforme from less malignant gliomas. Eur J Nucl Med Mol Imaging. 2012;39:760-770.

13. Persson M, Kjaer A. Urokinase-type plasminogen activator receptor (uPAR) as a promising new imaging target: potential clinical applications. Clin Physiol Funct Imaging. 2013;33:329-337.

14. Li D, Liu S, Shan H, Conti P, Li Z. Urokinase plasminogen activator receptor (uPAR) targeted nuclear imaging and radionuclide therapy. Theranostics. 2013;3:507-515.

15. Rasch MG, Lund IK, Almasi CE, Hoyer-Hansen G. Intact and cleaved uPAR forms: diagnostic and prognostic value in cancer. Front Biosci. 2008;13:6752-6762.

16. Jacobsen B, Ploug M. The urokinase receptor and its structural homologue C4.4A in human cancer: expression, prognosis and pharmacological inhibition. Curr Med Chem. 2008;15:2559-2573.

17. de Bock CE, Wang Y. Clinical significance of urokinase-type plasminogen activator receptor (UPAR) expression in cancer. Med Res Rev. 2004;24:13-39.

18. Salajegheh M, Rudnicki A, Smith TW. Expression of urokinase-type plasminogen activator receptor (uPAR) in primary central nervous system neoplasms. Appl Immunohistochem Mol Morphol. 2005;13:184-189.

19. Mohanam S, Gladson CL, Rao CN, Rao JS. Biological significance of the expression of urokinase-type plasminogen activator receptors (uPARs) in brain tumors. Front Biosci. 1999;4:D178-D187.

20. Yamamoto M, Sawaya R, Mohanam S, et al. Expression and localization of urokinase-type plasminogen activator receptor in human gliomas. Cancer Res. 1994;54:5016-5020.

21. Wykosky J, Hu J, Gomez GG, et al. A urokinase receptor-Bim signaling axis emerges during EGFR inhibitor resistance in mutant EGFR glioblastoma. Cancer Res. 2015;75:394-404.

22. Persson M, Madsen J, Jørgensen TJD, Jensen KJ, Kjaer A, Ploug M. Improved PET imaging of uPAR expression using new ${ }^{64} \mathrm{Cu}$-labeled cross-bridged peptide ligands: comparative in vitro and in vivo studies. Theranostics. 2013;3:618-632.

23. Persson M, Liu H, Madsen J, Cheng Z, Kjaer A. First ${ }^{18}$ F-labeled ligand for PET imaging of uPAR: in vivo studies in human prostate cancer xenografts. Nucl Med Biol. 2013;40:618-624.

24. Persson M, Madsen J, Ostergaard S, Ploug M, Kjaer A. ${ }^{68} \mathrm{Ga}$-labeling and in vivo evaluation of a uPAR binding DOTA- and NODAGA-conjugated peptide for PET imaging of invasive cancers. Nucl Med Biol. 2012;39:560-569.

25. Persson M, Madsen J, Ostergaard S, et al. Quantitative PET of human urokinasetype plasminogen activator receptor with ${ }^{64} \mathrm{Cu}$-DOTA-AE105: implications for visualizing cancer invasion. J Nucl Med. 2012;53:138-145.

26. Ploug M, Ostergaard S, Gardsvoll H, et al. Peptide-derived antagonists of the urokinase receptor. affinity maturation by combinatorial chemistry, identification of functional epitopes, and inhibitory effect on cancer cell intravasation. Biochemistry. 2001;40:12157-12168.

27. Cekanova M, Rathore K. Animal models and therapeutic molecular targets of cancer: utility and limitations. Drug Des Devel Ther. 2014;8:1911-1921.

28. Stockhausen MT, Broholm H, Villingshoj M, et al. Maintenance of EGFR and EGFRvIII expressions in an in vivo and in vitro model of human glioblastoma multiforme. Exp Cell Res. 2011;317:1513-1526.

29. Nedergaard MK, Kristoffersen K, Michaelsen SR, et al. The use of longitudinal ${ }^{18} \mathrm{~F}-\mathrm{FET}$ microPET imaging to evaluate response to irinotecan in orthotopic human glioblastoma multiforme xenografts. PLoS One. 2014;9:e100009.

30. Jacobsen B, Gardsvoll H, Juhl Funch G, Ostergaard S, Barkholt V, Ploug M. One-step affinity purification of recombinant urokinase-type plasminogen activator receptor using a synthetic peptide developed by combinatorial chemistry. Protein Expr Purif. 2007;52:286-296.

31. Lin L, Gardsvoll H, Huai Q, Huang M, Ploug M. Structure-based engineering of species selectivity in the interaction between urokinase and its receptor: implication for preclinical cancer therapy. J Biol Chem. 2010;285:10982-10992.

32. Illemann M, Bird N, Majeed A, et al. Two distinct expression patterns of urokinase, urokinase receptor and plasminogen activator inhibitor-1 in colon cancer liver metastases. Int J Cancer. 2009;124:1860-1870.

33. Rønne E, Hoyer-Hansen G, Brunner N, et al. Urokinase receptor in breast cancer tissue extracts: enzyme-linked immunosorbent assay with a combination of mono- and polyclonal antibodies. Breast Cancer Res Treat. 1995;33:199-207.

34. MacDonald TJ, DeClerck YA, Laug WE. Urokinase induces receptor mediated brain tumor cell migration and invasion. J Neurooncol. 1998;40:215-226.

35. Zhang X, Fei Z, Bu X, et al. Expression and significance of urokinase type plasminogen activator gene in human brain gliomas. J Surg Oncol. 2000;74:90-94.

36. Fung AS, Lee C, Yu M, Tannock IF. The effect of chemotherapeutic agents on tumor vasculature in subcutaneous and orthotopic human tumor xenografts. $B M C$ Cancer. 2015;15:112.

37. Nowosielski M, DiFranco MD, Putzer D, et al. An intra-individual comparison of MRI, $\left[{ }^{18} \mathrm{~F}\right]$-FET and $\left[{ }^{18} \mathrm{~F}\right]$-FLT PET in patients with high-grade gliomas. PLoS One. 2014;9:e95830. 